\title{
Experimental Study for the Thermal Conductivity of Micro and Nano fluids by Using Copper and Titanium Oxide
}

\author{
Dr. Muwafaq Shyaa Alwan \\ Network Engineering Department, Collage of Engineering, AL-Iraqia University, Baghdad / Iraq \\ E-mail: dr.muwafaqalwan@aliraqia.edu.iq
}

\begin{abstract}
In this article experimentally investigations have been carried out to study the effect of the size and type particles on the thermal conductivity of micro and nanofluids. The study investigated nanofluids and microfluids which containing copper $(\mathrm{Cu})$ and titanium oxide (TiO2) as well as in the size and type of micro and nanoparticles in distilled water as base fluid with different particles size and concentrations. The experimental results emphasized the enhancement of the thermal conductivity due to the nanoparticles presence in the fluid greater than microfluids, also shown the effect of the particle size and concentration on the thermal conductivity. It has been recognized that the addition of highly conductive particles can significantly increase the thermal conductivity of heat - transfer fluids. Particles in the micro and nano - size range have attracted the most interest because of their enhanced stability against sedimentation and, as a result, reduction in potential for clogging a flow system. Furthermore the results showed that, they obtained thermal conductivities doubtlessly revealed that a size and type particle was a key factor affecting conductive heat transport in suspensions. These results show noticeable enhancement in the thermal conductivity were evaluated to be $(7.66 \%, 2.35 \%)$ for the $\mathrm{Cu}, \mathrm{TiO} 2$ - distilled water nanofluid while reaches to $(3.23 \%, 1.02 \%)$ for the $\mathrm{Cu}$, $\mathrm{TiO} 2-\mathrm{distilled}$ water micro fluids at the concentration of $(5 \mathrm{vol} . \%)$ and at the room temperature. Moreover thermal conductivity was increased for the nanofluids and microfluids which contains large particle size compared with that contains small particle size. A good agreement was found between the experimental obtained data for this paper and other results from published papers.
\end{abstract}

Keywords: Nano fluid, Micro fluid, Thermal conductivity, Enhancement.

\section{Introduction}

Heat transfer fluids can exhibit significant increases in thermal conductivity with the addition of highly conductive particles. Recent attention has focused on micro - and nano particle suspensions because of their enhanced stability against sedimentation, reduction in potential for clogging a flow system, as well as the tantalizing possibility of unexpected enhancements in thermal conductivity. The later has been spurred by reports of large increases in the thermal conductivity in very - low - volume fraction nanoparticle (up to $100 \mathrm{~nm}$ in size) suspensions. For instance, the effective thermal conductivity of an ethylene-glycol-based nanofluid containing copper nanoparticles with diameters less than 10 $\mathrm{nm}$ was reported to increase by up to $40 \%$ at $0.3 \%$ vol of dispersed particles [1]. Another example is silver nanoparticles in water and toluene [2], where thermal conductivity enhancement of 5-21\% was observed at a loading of only $0.026 \%$ vol. The addition of less conductive aluminum oxide particles were reported to increase the resulting thermal conductivities of base fluids by up to $30 \%$ at particle volume fraction of $\mathrm{Al} 2 \mathrm{O} 3$ of 5\% [3], [4], 4\% [5] or 3\% [6]. In each case, the enhancements in thermal conductivity were reported to be greater than predicted by macroscopic theory for the given particle volume fraction and thermal conductivity. Among nanoparticle suspensions, those containing carbon nanotubes (CNTs) have attracted some of the most interest. Discovered in 1991, carbon nanotubes have already entered the realm of practicality, finding use in the aerospace, automotive and telecommunications industries because of their interesting characteristics. Single - walled carbon nanotubes are 100 times stronger than steel at one-sixth the weight and their thermal conductivity is about $5-10$ times greater than that of very conductive materials like aluminum or copper. Nanotubes can be electrical conductors or semiconductors depending on their crystal structure. Moreover, many physical properties of nanotubes, including their thermal conductivity, are expected to be highly anisotropic.

One of the emerging miniaturization techniques is the nanofluid technology which meets the shortcomings of the earlier used bulk fluids and conventional base fluids. Nanofluids exhibit large thermal conductivity compare to traditional (base) fluids and are suitable for heat transfer applications Choi et al. [7]; Das et al. [8]; Murshed et al. [9]; Xuan and $\mathrm{Li}$ [10]. There is a great attraction towards nanofluids because they are proved to be far more superior 
when compared to the conventional bulk fluids. Nanofluids offer promising heat transfer applications which is of major importance to industrial sectors including transportation, power generation, micro-manufacturing, electronics, engines, thermal therapy, heating, cooling, ventilation and air conditioning. Many of the reported anomalous enhancements in thermal conductivities in nanofluids were non reproducible Keblinski et al. [11].

Recent experimental studies suggest that nanofluids exhibit thermal conductivity enhancement within Maxwell's limit (Philip et al. [12]; Timofeeva et al. [13]; Eapen et al. [14];Shima et al. [15]. Zhang et al. [16] measured the effective conductivity and thermal diffusivity of Au/totuene, $\mathrm{A} 12 \mathrm{O} 3 /$ water, $\mathrm{TiO} 2 /$ water, $\mathrm{CuO} /$ water nanofluids using the transient short - hot - wire (SHW) technique, which was developed from the conventional transient hot wire (THW) technique and is based on the numerical solution of two dimensional transient heat conduction for a short wire with the same length - to - diameter ratio and boundary conditions as those used in the actual measurements. The diameters of $\mathrm{Au}$, $\mathrm{Al} 2 \mathrm{O} 3, \mathrm{TiO} 2$ and $\mathrm{CuO}$ spherical particles were 1.65, 20, 40 and $33 \mathrm{~nm}$, respectively. The effective thermal conductivities of the nanofluids show no anomalous enhancement and can be predicted accurately by the equations of the Hamilton and Crosser model. Liu et al. [17] measured the thermal conductivities of nanofluids containing CNTs $\mathrm{n}$ dispersed in ethylene glycol and synthetic engine oil. The increase of thermal conductivity is up to $12.4 \%$ for CNT - ethylene glycol suspensions at $1.0 \mathrm{vol} \%$ and $30 \%$ for CNT - synthetic engine oil suspensions at $2 \mathrm{vol} \%$. One possible reason for this is that the thermal conductivity is highly dependent on important factors such as the structure of the CNTs, clustering, temperature, etc. Further systematic research is necessary to obtain a whole map for the thermal conductivities of CNTs. Hwang et al. [18] compared the thermal conductivity of four kinds of nanofluids such as MWCNTs in water, $\mathrm{CuO}$ in water, $\mathrm{SiO} 2$ in water, and $\mathrm{CuO}$ in ethylene glycol. They found that the thermal conductivity of MWCNT nanofluid was increased up to $11.3 \%$ at $1 \mathrm{vol} \%$, which is relatively higher than that of the other groups of nanofluids. Zhang et al. [16] investigated the effective thermal conductivity and thermal diffusivity of CNT/water nanofluids using the transient short - hot - wire technique. The average length and diameter of CNTs are 10 $\mu \mathrm{m}$ and $150 \mathrm{~nm}$, respectively. However, the measured results demonstrate that the effective thermal conductivities of the nanofluids show no anomalous enhancements and can be predicted accurately by the unit - cell model equation of Yamada and Ota [19] for carbon nanofibers. There are few studies made on ultrasonic propagation in magnetic nanofluids by some researchers (Sayan and Ulrich [20]; Motozawa et al,[21]; Raj et al. [22]) there for no systematic research efforts have been carried out to compare the behavior of micro and nanofluids in terms of acoustical and thermal parameters. The fundamental understanding of exact mechanisms responsible for the anomalous values of ultrasonic wave propagation is unclear because of the lack of molecular level understanding of the ultrafine particles (Raj et al. [22]) that warrant systematic studies. A systematic study on the micro and nanofluids is required for the basic understanding of how the nanoparticles behave in fluids.

The objective of this work is an experimental exploration of the thermal conductivity of micro - and nano - particle and Compared thermal conductivity increase in suspensions containing micro - and nano - sized particles as well as study the type and particles agglomeration effect on the thermal conductivity of micro and nanoparticle suspensions.

\section{Theoretical formulation}

Currently, there is no reliable theory to predict the anomalous thermal conductivity of nanofluids. From the experimental results of many researchers, it is known that the thermal conductivity of nanofluids depends on parameters including the thermal conductivity of the base fluid and the nanoparticles, the volume fraction, the surface area, and the shape of the nanoparticles, and the temperature. There are no theoretical formulas currently available to predict the thermal conductivity of nanofluids satisfactorily [23]. For particle fluid mixtures, numerous theoretical studies have been conducted dating back to the classical work of Maxwell. Yu and Choi [24] proposed a modified Maxwell considering to account the effect of the nano - layer by replacing the thermal conductivity of solid particles $\mathrm{kp}$ in Eq. (1) with the modified thermal conductivity of particles $\mathrm{kp}$, which is based on the so called effective medium theory. The thermal conductivity of nanofluid is:

$$
\mathrm{k}_{\mathrm{nf}}=\left[\frac{\mathrm{k}_{\mathrm{p}}+2 k_{b}+2\left(k_{p}-k_{b}\right)(1+\beta)^{3} \Phi}{k_{p}+2 k_{b}-2\left(k_{p}-k_{b}\right)(1+\beta)^{3} \Phi}\right] k_{b}
$$

Where $k_{p}$ is the thermal conductivity of the particle, $\mathrm{kb}$ is the thermal conductivity of the base fluid and $\Phi$ is the particle volume fraction in the suspension, $\beta$ ratio of nano - layer thickness to the original particle radius. Normally $\beta=0.1$

The thermal conductivity of the nanofluid is calculated from Hamilton\& Crosser [25] model for particles uniformly dispersed in a continuum medium using the following equation:

$$
k_{n f}=\frac{k_{p}+(n-1) k_{b}-(n-1)\left(k_{b}-k_{p}\right)}{k_{p}-(n-1) k_{b}+\left(k_{b}-k_{p}\right) \Phi}
$$

$\Psi=\Psi=\frac{3}{\Psi}$ Where: $\mathrm{knf}$ is the thermal conductivity of the nanofluid, $\mathrm{kp}$ is the thermal conductivity of the nanoparticles, $\mathrm{kb}$ is the thermal conductivity of the base fluid and $\mathrm{n}$ is the empirical shape factor given by, and is the particle sphericity ( 1 for spherical particles). Furthermore, The experimental thermal conductivity data for an alumina nanofluid were initially reported by Williams et al,[26]. as Equation (3). 


$$
k_{n f}(\Phi, T)=k_{b}(T)(1+4.5503 \Phi)
$$

The applicable temperature range of this equation is $20^{\circ} \mathrm{C}<T<80^{\circ} \mathrm{C}$, with volumetric loadings up to $6 \%$ for alumina.

One well - known formula for calculating the thermal conductivity of nanofluid is Timo Feera et al. [13].

$$
k_{n f}=(1+3 \Phi) k_{b}
$$

\section{Experimental investigation}

\section{A. Sample Preparation}

Nanofluid samples were prepared by dispersing pre weighed quantities of dry particles in distilled water. The $\mathrm{pH}$ of each aqueous mixture was measured; the mixtures were then subjected to ultrasonic mixing (Sonics \&Materials, Inc. Vibra - Cell VCX 750) for one hour to break up any particle aggregates. The acidic $\mathrm{pH}$ is much less than the iso electric point of these particles $(6-8$ for titanium oxide and $5.5-8$ for copper), thus ensuring a positive surface charge on the particles. The surface charge enhanced repulsion between the particles, which resulted in uniform dispersions for the duration of the experiments. Figure (1) depicted an aqueous nanofluids Oxide (TiO2) and copper $(\mathrm{Cu})$. The same preparation for micofluids and Fig.(2) shows an aqueous micofluids Oxide (TiO2) and copper $(\mathrm{Cu})$.
(A)
(B)
(C)

Figure (1) Aqueous nanofluids (A) containing Cupper $(\mathrm{Cu})$, (B) containing Titanium oxide $\left(\mathrm{TiO}_{2}\right)$ nanoparticles and $(\mathrm{C})$ distilled water

(A)

Figure (1) Aqueous micro fluids (A) containing Cupper $(\mathrm{Cu})$ and $(\mathrm{B})$ containing Titanium oxide $\left(\mathrm{TiO}_{2}\right)$ micro particles

\section{B. Thermal conductivity Measurement}

Since thermal conductivity is the most important parameter responsible for enhanced heat transfer many experimental works been reported on this aspect. Lee's disc technique was used for the measurement of the thermal conductivity for nanofluids and microfluds. The apparatus which is used in the measurement of the thermal conductivity is shown in the Figs.(3,4-A and, 4 - B). Figs.(3) reveal the built - up cell which is used to measure the thermal conductivity, the cell contains three parts, on the two sides of the cell there is two copper discs (1 and 2) as shown in the figure. While the third part of the cell located between the two copper discs and contains the experimental fluid. The apparatus placed in a tightly closed location to keep the temperature of the environment at constant value. Fig.(4 - B) represents the test apparatus (Lee's disc apparatus) type (Griffin and George) with tested sample disc and some accessories to measure the temperature on both sides of the sample disc in order to calculate the thermal conductivity, the heater is switch on from the power supply with( $\mathrm{V}=6 \mathrm{~V}$ and I $=0.2 \mathrm{~A}$ ) to heat the copper discs ( 2 and 3 ) and the temperature of the all discs increases in nonlinear relationships and at different rates with the time according to its position from the heat source, and the temperatures were recorded every (5 minutes) until reach to the equilibrium temperature of all discs. Then the thermal conductivity can be calculated by using the following form Murthy et al [26] and Rondeauz \& Bready [27]:

$$
K\left[\frac{T_{2}-T_{1}}{d s}\right]=e\left[T_{1}+\frac{2}{r}\left(d_{1}+\frac{1}{2} d s\right) T_{1}+\frac{1}{2} d s T_{2}\right]
$$

And can calculate the value of e as follows:

$$
I V=\pi r^{2} e\left(T_{1}+T_{3}\right) 2 \pi r e\left[d_{1} T_{1}+\frac{1}{2} d s\left(T_{1}+T_{2}\right)+d_{2} T_{2}+d_{3} T_{3}\right]
$$

The experimental results for the thermal conductivity were compared with the equations or models of thermal conductivity developed by researchers such as $\mathrm{Yu}$ and Chio
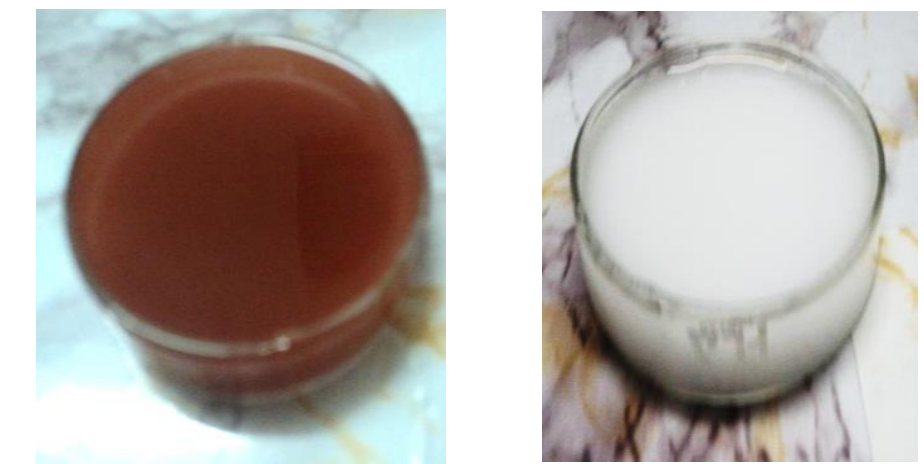

model [23], Hamilton \& Crosser model [24], Wesley Charles - Williams model [25] and Timo Feeva et al model [13],

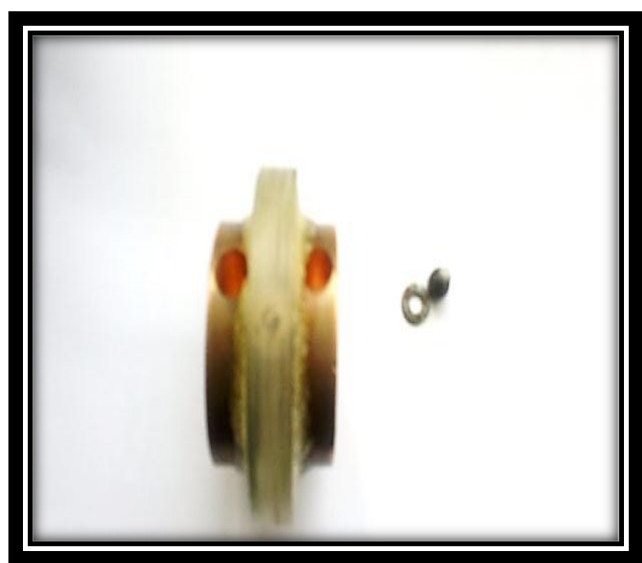


Figure (3) Testing cell

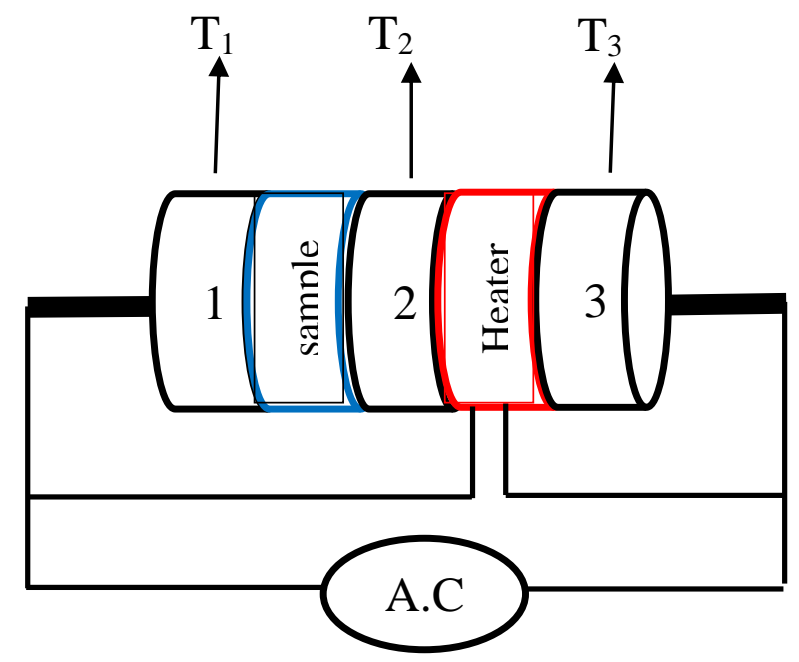

Figure $(4-\mathrm{A})$ : Schematic diagram for Lee's disc method
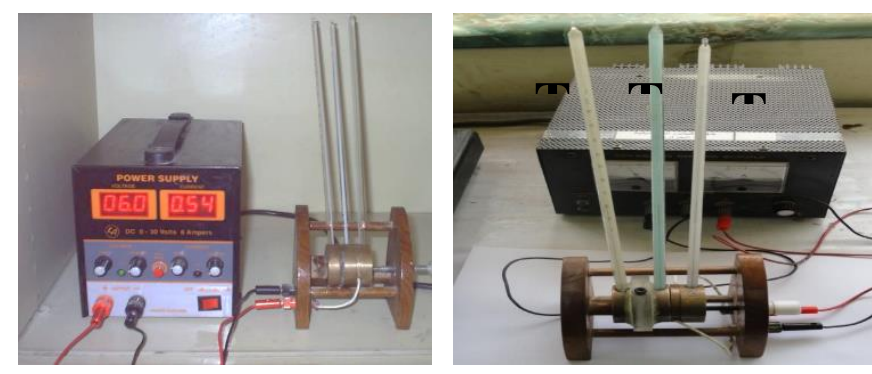

Figure (4 - B) Thermal conductivity test Apparatus

\section{Results and Discussion}

In order to verify the accuracy and the reliability of the experimental apparatus, at start the thermal conductivity are experimentally measured for distilled water, ethylene glycol, methanol and ethanol before obtaining those of micro and nanofluids $(\mathrm{Cu}+\mathrm{DW}),(\mathrm{TiO} 2+\mathrm{DW})$. Fig. 5 shows the variation of theoretical values with experimental values for thermal conductivity to four types of fluids (distilled water, ethylene glycol, methanol, and ethanol). Also it is seen from this figure, the deviation of the experimental data from the theoretical less than $5 \%$.

Figs. (6 and 7) show that the ratio of the thermal conductivity ( $\mathrm{K} \mathrm{nf} / \mathrm{K}$ base) increases significantly with the increasing of concentration, and the relation between the thermal conductivity with the concentration is a linear relation. The enhancement in the thermal conductivity were evaluated to be $(7.66 \%, 2.35 \%)$ for the $\mathrm{Cu}, \mathrm{TiO} 2-$ distilled water nanofluid respectively, while reaches to $(3.23 \%, 1.02 \%)$ for the $\mathrm{Cu}, \mathrm{TiO} 2$ - distilled water micro fluid at the concentration of $(0.05$ vol. \%). The results obtained from these figures indicate that the copper particles have thermal conductivity higher than that of the titanium oxide particles. The experimental results for this investigation are compared with other data from published papers at the same field, very good agreement is found between the experimental data and model R.L. Hamilton, O.K. Crosser [11], and it is the closest to practical by difference does not exceed $1.25 \%$.

Thermal conductivity was increased for the nanofluids and microfluids which contains large particle size compared with that contains small particle size as shown in figs. ( 8 and 9), these figures show the effect of the particle size on the thermal conductivity. Figs. (10 and 11) show a comparison between the experimental data for thermal conductivity of $(\mathrm{Cu}, \mathrm{TiO} 2$ - distilled water) nanofluids and micro fluids at $(\mathrm{dp}=20,30,50 \mathrm{~nm}$ and 20,30,50 $\mu \mathrm{m})$ particle size, this comparison shows the enhancement of the thermal conductivity for the two types of nanofluids are greater than two types of microfluids $(\mathrm{Cu}, \mathrm{TiO} 2$ - distilled water) and the effect of the particle size on this enhancement. It has been recognized that the addition of highly conductive particles can significantly increase the thermal conductivity of heat transfer fluids. Particles in the micro and nano - size range have attracted the most interest because of their enhanced stability against sedimentation and, as a result, reduction in potential for clogging a flow system. Furthermore the results showed that, they obtained thermal conductivities doubtlessly revealed that a size and type particle was a key factor affecting conductive heat transport in suspensions. For nanofluids, despite the promise of enhanced stability due to the nanoscale size of particles, particle agglomeration state can have a profound effect on the resulting thermal conductivity of the suspension. Figs.(12) and (13) reveal the experimental data of thermal conductivity to nanofluids and microfluids for two types of particles $\mathrm{Cu}, \mathrm{TiO} 2-$ distilled water. These figs indicated that thermal conductivity of nanofluids is greater than thermal conductivity of microfluids due to the small nano scale for nanoparticles. 


\section{Conclusion}

The present work has reached to the following conclusions:-

1. Thermal conductivity increases with the increasing the concentration of nanofluids and microfluids.

2. Thermal conductivity increases with the increasing of the particle size for the nanofluids and microfluids.

3. Nano and micro particle type (material type) plays an important role in the thermal conductivity enhancement.

4. Thermal conductivity by using metallic such as $(\mathrm{Cu})$ is greater than nonmetallic $\left(, \mathrm{TiO}_{2}\right)$ for nano and microfluids.

5. The nano and micro particles size was a key factor affecting conductive heat transport in suspensions.

\section{Nomenclature}

\begin{tabular}{|c|c|c|}
\hline d & Thickness of the discs & $\mathrm{mm}$ \\
\hline $\mathrm{l}_{1}, \mathrm{~d}_{2}$ & $\begin{array}{c}\text { Thickness of the discs of one } \\
\text { and two }\end{array}$ & $\mathrm{mm}$ \\
\hline ds & Thickness of the sample & $\mathrm{mm}$ \\
\hline $\mathrm{e}$ & Heat loss & Watt \\
\hline I & Current & $\mathrm{A}$ \\
\hline V & Voltage & $\mathrm{V}$ \\
\hline K & Thermal conductivity & $\mathrm{W} / \mathrm{m}^{2} . \mathrm{k}$ \\
\hline $\mathrm{n}$ & Empirical shape factor & - \\
\hline $\mathrm{r}$ & The radius of the disc & $\mathrm{mm}$ \\
\hline DW & Distilled water & - \\
\hline $\begin{array}{l}\mathrm{T} 1 \\
\mathrm{~T}_{2}\end{array}$ & $\begin{array}{l}\text { The temperatures of the } \\
\text { through discs. }\end{array}$ & $\mathrm{K}$ \\
\hline$\Phi$ & Volume fraction & $\%$ \\
\hline & subscripts & \\
\hline $\mathrm{nf}$ & Nanofluid & - \\
\hline $\mathrm{p}$ & Nanoparticles & - \\
\hline$b$ & Base & - \\
\hline
\end{tabular}

\section{References}

1. Eastman, J. A., Choi, S. U. S., Li, S., Yu, W., and Thompson, L. J., 2001, "Anomalously increased effective thermal conductivities of ethylene glycol based nanofluids containing copper nanoparticles," Appl. Phys. Lett., 78(6), pp.718-720.

2. Patel, H. E., Das, S. K., Sundararajan, T., Sreekumaran, N. A., George, B., and Pradeep, T., 2003, "Thermal conductivities of naked and monolayer protected metal nanoparticle based nanofluids: Manifestation of anomalous enhancement and chemical effects," Appl. Phys. Lett., 83(14), pp. 2931-2933.

3. Xie, H., Wang, J., Xi, T., Liu, Y., Ai, F., and Wu, Q., 2002, "Thermal conductivity enhancement of suspensions containing nanosized alumina particles", J. Appl.Phys., 91(7), pp. 4568-4672.

4. Xie, H., Wang, J., Xi, T., Liu, Y., and Ai, F., 2002, "Dependence of the thermal conductivity of nanoparticle-fluid mixture on the base fluid," J. Mater. Sci. Lett., 21(19), pp. 1469-1471.

5. Das, S. K., Putra, N., Thiesen, P., and Roetzel,W., 2003, "Temperature dependence of thermal conductivity enhancement for nanofluids," J. Heat Transf., 125, pp.567-574.

6. Lee, S., Choi, S., Li, S., and Eastman, J. A., 1999, "Measuring thermal conductivity of fluids containing oxide nanoparticles," J. Heat Transf., 121(2), pp. 280-289.

7. Choi SUS, Zhang ZG, Yu W, Lockwood FE, Grukle EA, 2001, "Anomalous thermal conductivity enhancement in nano-tube suspensions", Appl Phys Lett 79: (2001) 2252-2254.

8. Das SK, Putra N, Thiesen P, Roetzel W, 2003, " Temperature dependence of thermal conductivity enhancement for nanofluids". J Heat Transfer 125: 567-574.

9. Murshed SMS, Leong KC, Yang C, 2005, "Enhanced thermal conductivity of $\mathrm{TiO} 2-$ water based nanofluids", Int J Therm Sci 44: 367-373.

10. Xuan Y, Li Q, 2000, "Heat transfer enhancement of nanofluids" Int J Heat Fluid Flow 21, 58-64 .

11. Keblinski P, Eastman JA, Cahill DG, 2005, "Nanofluid for thermal transport", Mater Today 8: 36-44.

12. Philip J, Shima PD, Raj B, 2007, "Experimental evidence for enhancement of thermal conductivity under clustering", Appl Phys Lett 91: 203108. 
13. Timofeeva EV, Gavrilov AN, McCloskey JM, Tolmachev YV, 2007, "Thermal conductivity and particle agglomeration in alumina anofluids: experiment and theory", Phys Rev E 76: 061203-1$061203-16$.

14. Eapen J, Williams WC, Buongiorno J, Hu L, Yip S, Rusconi R, Piazza R, 2007, "Mean-field versus microconvection effects in nanofluid thermal conduction", Phys Rev Lett 99: 095901.

15. Shima PD, Philip J, Raj B, 2009, "Role of micro convection induced by Brownian motion of nanoparticles in the enhanced thermal conductivity of stable nanofluids", Appl Phys Lett 94: 223101.

16. Zhang, X., Gu, H., and Fujii, M. 2007, "Effective thermal conductivity and thermal diffusivity of nanofluids containing spherical and cylindrical nanoparticles", Experimental Thermal and Fluid Science, 31,No. 6, 593-599.

17. Li, X., Zhu, D., and Wang, X., 2007, "Evaluation on dispersion behavior of the aqueous copper nano suspensions", Journal of Colloid and Interface Science, 310, no. 2, 456-463.

18. Hwang, Y. J., Ahn, Y. C., Shin, H. S., Lee, C. G., Kim, G. T., Park, H. S., and Lee, J. K., 2005, "Investigation on characteristics of thermal conductivity enhancement of nanofluids", Current Applied Physics, 6, no. 6, 1068-1071.

19. Yamada, E. and Ota, T., 1980, "Effective thermal conductivity of dispersed materials", Wärme - und Stoffübertragung, 13, $27-37$.

20. Sayan P, Ulrich J, 2002, "The effect of particle size and suspension density on the measurement of ultrasonic velocity in aqueous solutions", Chem ,Eng Process 41:,281-287.

21. Motozawa M, lizuka Y, Sawada T, 2008, "Experimental measurements of ultrasonic propagation velocity and attenuation in a magnetic fluid", J Phys Condens Matter 20:204117. Doi: 10.1088/0953 - 8984/20/20/204117.

22. Raj B, Philip J, Rajkumar KV, Kalyanasundaram P, 2006, "Effect of magnetic field on ultrasonic velocity in a magnetic nanofluid", Proc Indian Natl Sci Acad 72: 145-151.

23. Xiang - Qi Wang; Arun S. Mujumdar, 2008, "A review on nanofluids - part I: theoretical and numerical investigations", Braz. J. Chem. Eng. vol.25 no. 4 São Paulo Oct./Dec.

24. W. Yu, S.U.S. Choi, 2003, "The role of interfacial layers in the enhanced thermal of Nano fluids: a renovated Maxwell model", Journal of Nano particle Research 5 (1-2), 167-171.
25. R.L. Hamilton, O.K. Crosser, 1962, "Thermal conductivity of heterogeneous two component systems", I\&EC Fund am $1,182-191$.

26. Wesley Charles Williams, 2006, "Experimental and theoretical investigation of transport phenomena in Nano particle Colloids (Nano fluids)", Department of Nuclear Science and Engineer at Massachusetts Institute of Technology.

27. Murthy BSR, Dr. A. Ram Krisnna and Rama Krisnna B. v., 2004, "Thermally analysis of Epoxy Based Fiber Reinforced", IE (I) Journal -Mc, vol.84.

28. Rondeauz F. Ph., Bready J. m. Rey., 2001, "Thermal conductivity measurement of Epoxy system at low Temperature", Cryogen tic engineering conference (CFC). USA. 


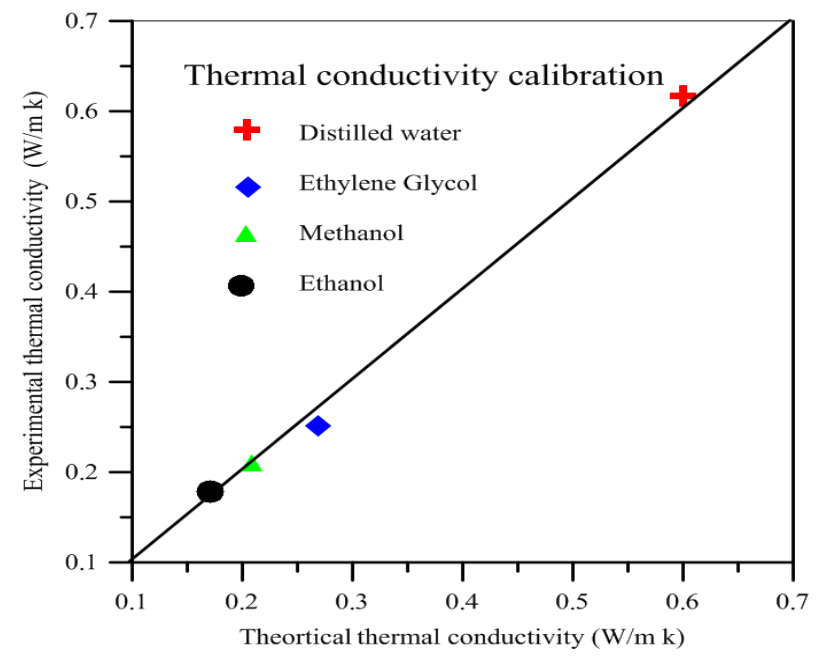

Figure (5) Thermal conductive calibration results

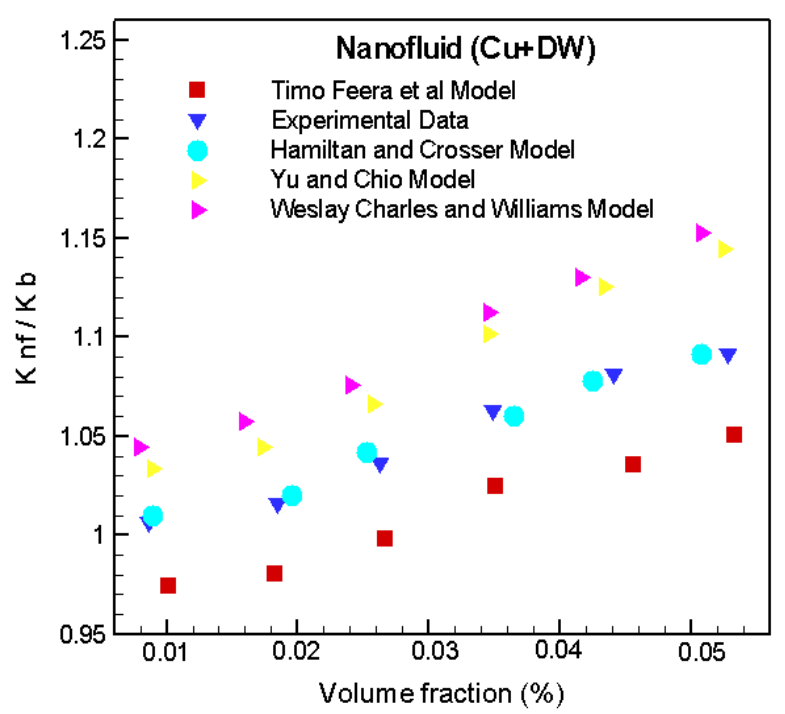

Figure (6) Thermal conductivity ratio of distilled water + based $\mathrm{Cu}$ nanofluid

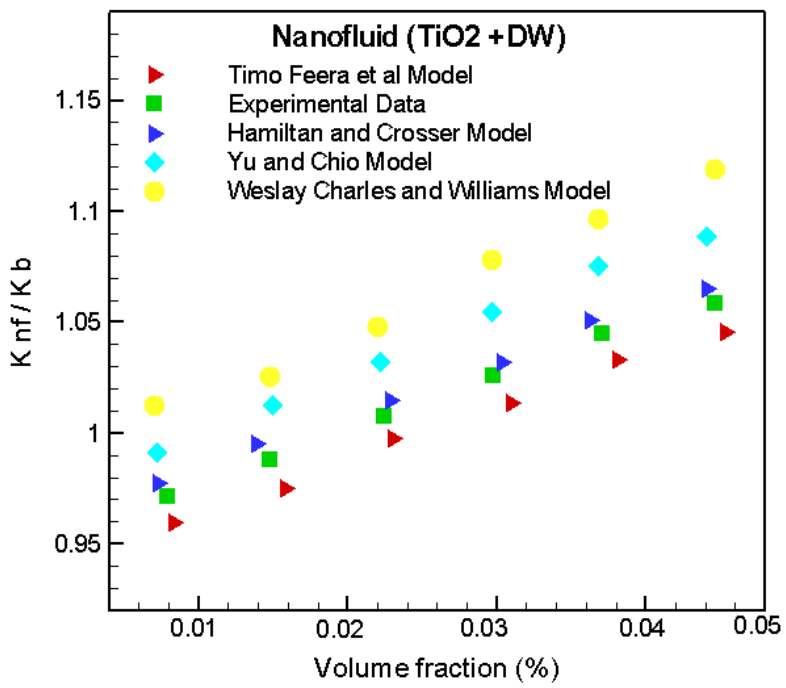

Figure (7) Thermal conductivity ratio of distilled water + based $\mathrm{TiO}_{2}$ nanofluid

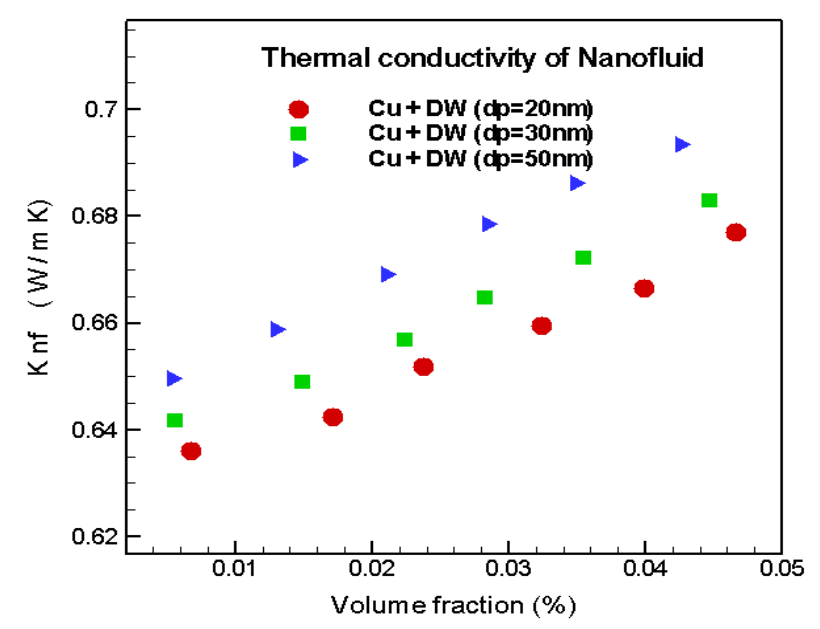

Figure (8) Thermal conductivity ratio of distilled water + based $\mathrm{Cu}$ nanofluid With different particles diameter 


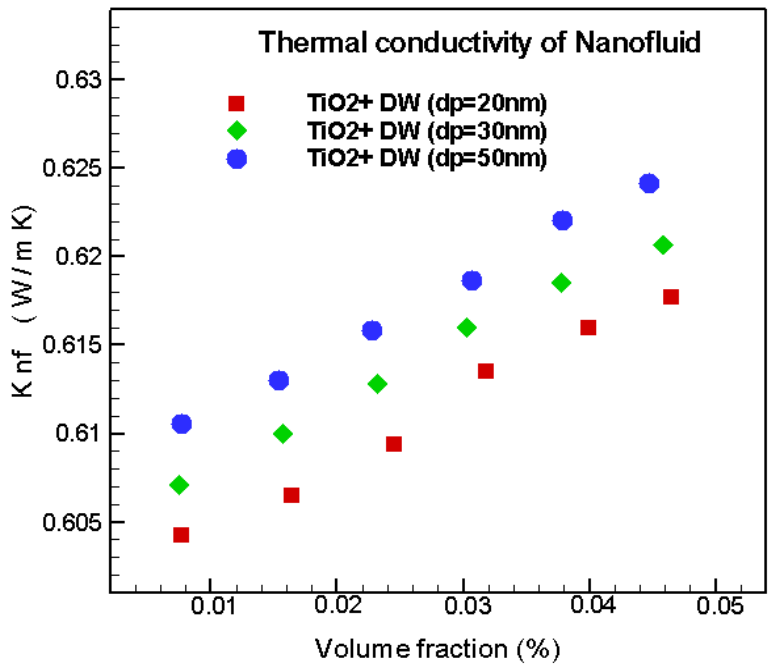

Figure (9) Thermal conductivity ratio of distilled water + based $\mathrm{TiO}_{2}$ nanofluid With different particles diameter

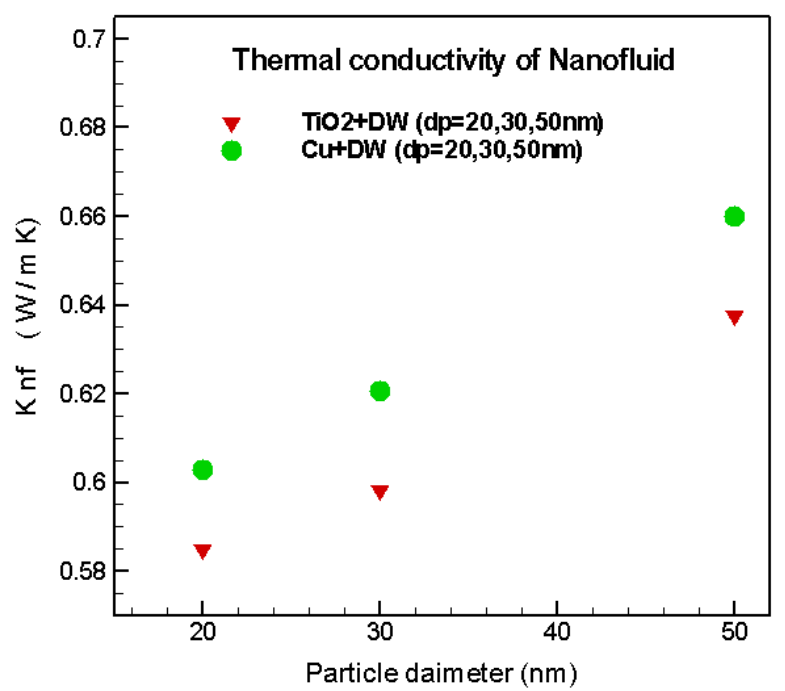

Figure (10) Experimental data for thermal conductivity of nanofluids versus particle size

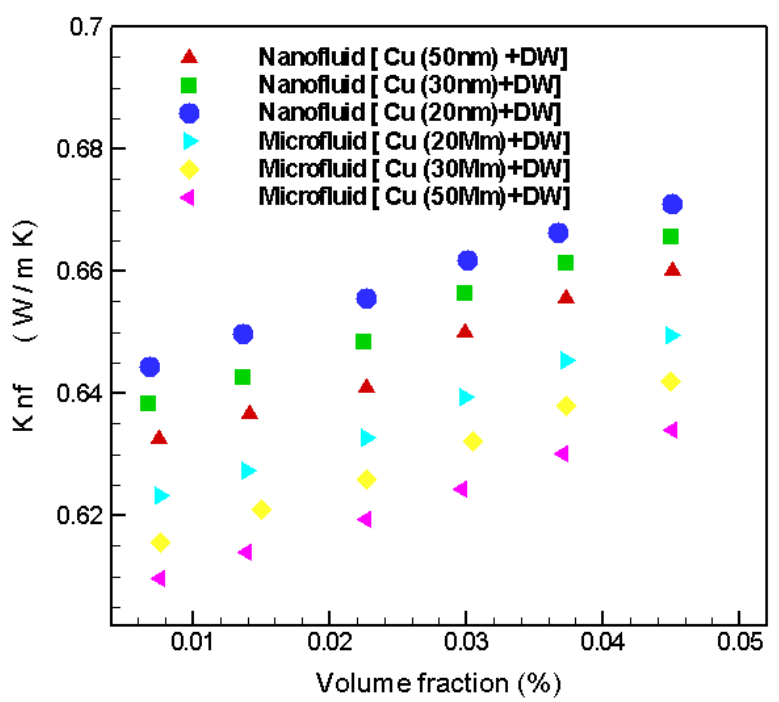

Figure (11) Experimental data for thermal conductivity of microfluids versus particle size

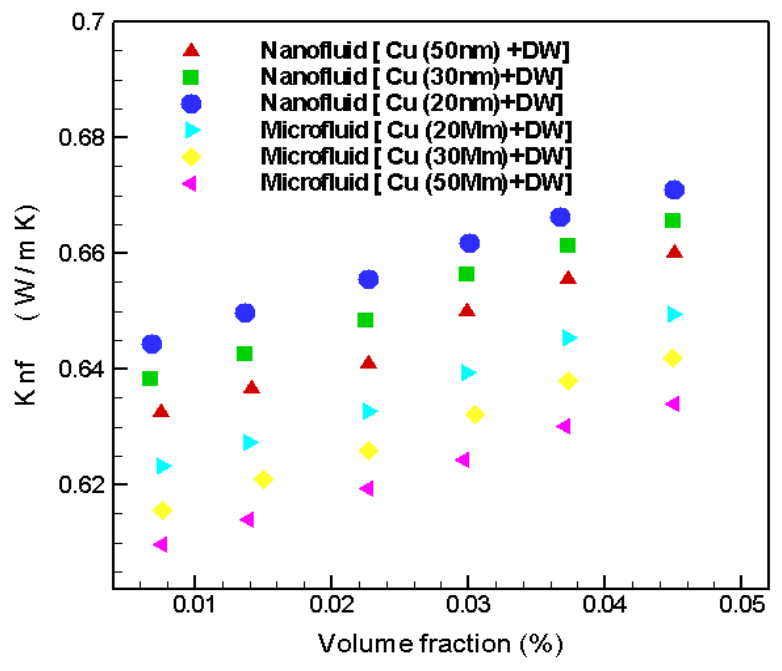

Figure (12) Experimental data for thermal conductivity of microfluid $(\mathrm{Cu}+\mathrm{DW})$ and nanofluid $(\mathrm{Cu}+\mathrm{DW})$ for different particle size 


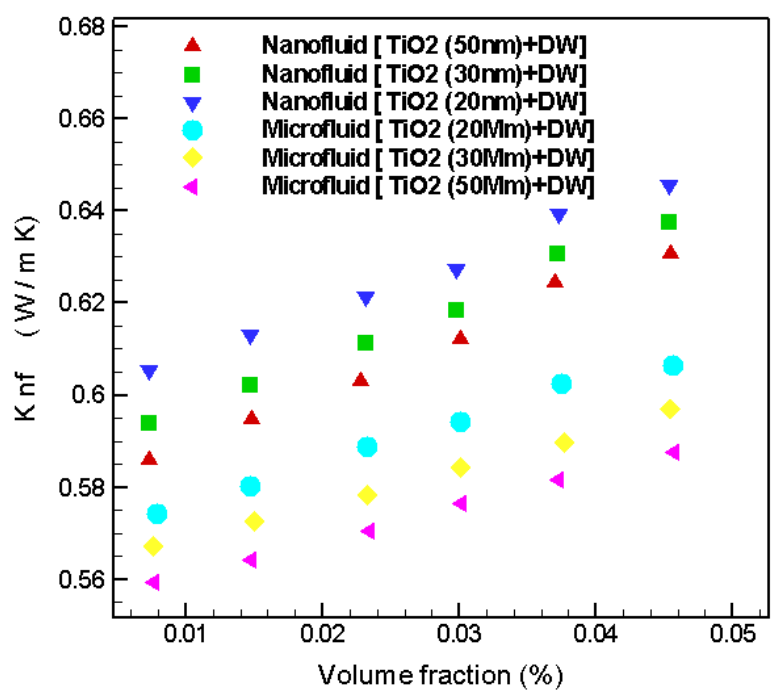

Figure (13) Experimental dat for thermal conductivity of microfluid $\left(\mathrm{TiO}_{2}+\mathrm{DW}\right)$ and nanofluid $\left(\mathrm{TiO}_{2}+\mathrm{DW}\right)$ for different particle size 